\title{
Alteration of Isotopic Composition of Organic Material During Tar Formation
}

\author{
Dr. Louis Elrod and Dr. Edmond Shtepani* \\ "Intertek Westport Technology Center
}

Asphalt-rich or heavy oil (tar, bitumen, pyrobitumen, etc.) can form and accumulate within geologic systems by a number of different processes. These processes include:

- Migration and emplacement of immature asphalt-rich bitumen

- Precipitation of asphaltenes from oil

- Biodegradation of oil

- Water-washing of oil

- Phase separation of oil

- Gravity segregation of oil

- Evaporation of light ends from oil

- Thermal alteration of oil or bitumen

These processes can operate individually or jointly to produce the wide variety of heavy hydrocarbons observed world-wide. Determination of the origin of heavy hydrocarbons is critical for mitigating the effects of the heavy deposits on production and avoiding such accumulations during exploration. Because the isotopic composition of hydrocarbons can be dramatically affected by the various tar formation processes, assessment of the isotopic composition of heavy hydrocarbons and hydrocarbon fractions can provide a critical tool for determination of tar origin. This paper discusses and presents examples of the utility of isotope data for assessing tar origin. 